\title{
Unwanted foreign doctors: what is not being said about the brain drain
}

\author{
Saad Shafqat Anita K M Zaidi
}

J R Soc Med 2005;98:492-493

To fresh medical graduates in developing countries, securing a postgraduate training spot in a British or American academic medical centre represents the realization of a dream that has been passionately stoked for years. There are many of us. We come mostly from the Indian subcontinent, from the Far East (especially the Philippines and China), from Middle Eastern countries such as Egypt, Iran and Syria and, more recently, from sub-Saharan Africa. Our countries are able to provide decent undergraduate medical education, but often little beyond. Motivated by professional and material lures, we come to the US, UK and Canada and, increasingly, Australia, New Zealand, South Africa and the Republic of Ireland. Often we fill a need, making up the numbers or stepping in where others are reluctant. Sometimes we come across opportunities to fulfil professional ambitions and we seize them.

This enterprise is driven by bedrock values that every human being holds dear: progress, advancement, and the freedom to be your best. We seek no favours and demand no concessions. We do expect that, once the examination and licensing hurdles are overcome, we will be treated on equal footing with local graduates and allowed to compete for jobs that will be filled through merit and respect for fair play. We do not think this is too much to ask for.

The influx of foreign medical graduates into the industrialized West has been going on for decades. A straightforward supply-demand equation, it is sustained by multiple synergistic forces. While competent physicians are produced (in many cases, overproduced) in poorer countries, the local environment struggles to absorb or even value them; meanwhile, unmet medical manpower needs beckon from the developed world. The phenomenon has economic, socio-demographic, ethical and moral implications, but the human dimension may be the most important of all. There is an ethical and moral cost to this exodus of qualified physicians from the developing world, but, on the other hand, what about the ethics and morality of denying people their dreams? This is the coarse underbelly of the foreign medical graduate debate.

Aga Khan University Medical College, Karachi 74800, Pakistan

Correspondence to: Dr Shafqat

E-mail: saad.shafqat@aku.edu
Opponents of medical migration have tried to cast this debate in terms of a moral imperative for strengthening the developing world's health systems. But there are far more effective ways to promote healthcare in the developing world, for example through assistance with infrastructure, biotechnology, sanitation, economic development, and openhanded debt relief. Simply forcing qualified physicians to stay put in impoverished societies where they cannot be absorbed will have little impact on the health of the world's poor. Far from being a moral impulse, this rather looks like selfishness, with the industrialized countries opening and shutting the door according to their own needs.

On this side of the debate, life is becoming harder. Doctors who entered postgraduate training in the US and UK in the 1950s and 1960s speak of a time when qualifying examinations were trivial, visa issues a formality, and transition to a life in the West almost effortless. Positions were secured through correspondence or telephone and hospital administrators received trainees at the airport. Over the years, the hurdles have multiplied, and now cost a fortune. The qualifying examinations, application procedures, and interview-related travel expenses come out in the neighbourhood of $£ 6000$, with the more determined medical students spending an additional $£ 3000$ on overseas elective rotations aimed at improving their applications.

The newest twist is the global climate of fear, because in a world where virtually everyone is a potential terror suspect, the term 'foreign' takes on a raw meaning. Foreign medical graduates are now facing ruthless and whimsical visa impasses that cannot be appealed. Embassies of the United States are the worst offenders, and physicians from predominantly Muslim countries may be more seriously affected. In Pakistan, bright young physicians with competitive credentials are routinely and-from all available evidence - randomly denied visas to travel to the USA for the required clinical skills examination and for prescheduled job interviews at American hospitals. It is happening to men and women alike. The explanation given is that the visa officer was 'not satisfied'. You may re-apply but there is a US $\$ 200$ fee, and experience advises not to hold your breath. Despite everything being in order, one out of every four or five such applications is now being rejected. If the applicant begins pleading, the visa officer switches off the voice link across the glass. 
Not long ago, two former students who appeared headed for such a disastrous fate came to see us. They had been offered residency positions by two leading university hospitals in the USA, but were unable to report on time because the embassy had sent their passports for a seemingly endless 'FBI check'. Enquiries at the embassy yielded nothing. The hospitals were supportive, but the young doctors knew they were trying their employer's patience. Eventually, an audience with officials from the US embassy was arranged. When the head of the group, a grave and unsmiling gentleman with an air of authority, was asked to help with the physicians predicament, his answer shocked us with its arrogance. 'Like all great countries, we have over-reacted,' he said, referring to the backlash after $9 / 11$. The message was to sit tight and simply allow the great American response to play itself out, even if it means watching your hopes disappear. Their visas eventually did come through. Both doctors had common Muslim names that cross-matched with a terrorist database, and it took many months to get sorted. The hospitals generously accommodated them nearly a year after they were due to start, but are now reluctant to entertain foreign applications again. Surely, there must be better ways to regulate the foreign physician supply line?

Gains from medical migration are aplenty. Most directly, recipient countries are able to recruit foreign medical graduates for service, academic and research needs. Perhaps even more importantly, a small proportion of foreign physicians eventually do return to their home countries. Rigorous numbers are hard to come by, but estimates suggest around 200 US-trained and several-fold more UK-trained medical consultants and specialists now settled and working in Pakistan alone. That such professionals are wasted back in their home countries is a myth. Admittedly, repatriation is tricky - requiring large reserves of motivation and resources-but those who return contribute hugely, becoming standard-setters for clinical practice, academic leaders in education and research and, increasingly, influential voices in health policy and public health.

There are always at least two solutions to any problem - the definitive one, and the one where you brush it under the carpet. If the industrialized world truly desires to approach this issue definitively, its health experts should collaborate with counterparts from the developing world to work towards a day when foreign medical graduates can get world-class specialist training and a quality of life commensurate with professional accomplishment without leaving home. A model that shows promise is the establishment of Western-style academic medical centres that interpret the health-care mandate broadly and transparently adhere to global standards of care delivery. Western governments can facilitate this through grant monies, technology transfer and strategic know-how. Public-private partnerships can emerge that, like a rising tide, could lift societal development in other areas. That would certainly be better than dispensing heartless admittance policies from a lofty perch or hiding behind a moral fig-leaf that barely covers anything. 